\title{
HUBUNGAN LINGKAR SKROTUM DENGAN KUALITAS SEMEN SAPI KUANTAN RIAU
}

\section{The Correlation Between Scrotal Circumference and Semen Quality of Riau Kuantan Cattle}

\author{
Jiyanto ${ }^{1}$ dan Pajri Anwar ${ }^{1}$ \\ ${ }^{1}$ Program Studi Peternakan, Universitas Islam Kuantan Singingi \\ Email: aji_jiyanto16@yahoo.com
}

\begin{abstract}
INTISARI
Tujuan dari penelitian ini untuk mengetahui hubungan lingkar skrotum dengan kualitas semen sapi Kuantan Riau. Penelitian dilaksanakan di Kecamatan Benai, Kabupaten Kuantan Singingi. Materi yang digunakan adalah 15 ekor sapi Kuantan jantan. Parameter yang diamati adalah ukuran lingkar skrotum, kualitas semen dan hubungan lingkar skrotum dengan kualitas semen. Hasil penelitian ini menunjukkan bahwa ukuran lingkar skrotum sapi Kuantan 23,06 cm; viabilitas 76,67\%; dan motilitas 58\%. Hasil analisis regresi yang dilakukan pada lingkar skrotum terhadap viabilitas dan motilitas spermatozoa sapi Kuantan tidak menunjukkan perbedaan yang nyata $(\mathrm{P}>0,05)$. Hubungan antara lingkar skrotum dengan viabilitas spermatozoa sapi Kuantan memiliki korelasi yang sedang yaitu 0,40. Hubungan lingkar skrotum dengan motilitas spermatozoa sapi Kuantan memiliki korelasi yang rendah yaitu 0,22. Persamaan regresi yang diperoleh untuk mengetahui hubungan antara lingkar skrotum dengan viabilitas dan motilitas spermatozoa adalah $\mathrm{Y}=45,44+1,35 \mathrm{X}$ dan $\mathrm{Y}=44,77+0,57 \mathrm{X}$. Hasil penelitian ini menunjukkan bahwa lingkar skrotum tidak dapat di jadikan sebagai penentu kualitas spermatozoa sapi jantan Kuantan Riau.
\end{abstract}

Kata kunci: Kualitas Semen, Lingkar Skrotum, Sapi Kuantan

\begin{abstract}
The aim of this study was to determine the correlation between scrotal circumference and semen quality of the Riau Kuantan cattle. The study was conducted in Benai District, Kuantan Singingi Regency. The material used was 15 Kuantan bulls. The parameters observed were scrotal circumference, semen quality and the correlation between scrotal circumference and semen quality. The results of this study indicated that the size of Kuantan cattle scrotum circumference was $23.06 \mathrm{~cm}$; viability $76.67 \%$; and motility 58\%. The results of regression analysis which conducted on scrotal circumference for the viability and motility showed not significant $(P>0.05)$. The correlation between scrotal circumference with spermatozoa viability of Kuantan cattle showed a moderate correlation of 0.40 . The relationship between scrotal circumference with spermatozoa motility in Kuantan cattle showed a low correlation of 0.22 . The regression equation obtained to determine the relationship between scrotal circumference with viability and motility of spermatozoa were $Y=45.44+1.35 X$ and $Y=44.77+0.57 X$, respectively. The results of this study indicated that scrotal circumference cannot be made as determinant of spermatozoa quality of in Riau Kuantan bulls.
\end{abstract}

Keywords: Scrotum Linkage, Cement Quality, Kuantan Bull

\section{PENDAHULUAN}

Sapi Kuantan merupakan ternak lokal Indonesia yang berasal dari Kabupaten Kuantan Singingi, Provinsi Riau. Asal-usul sapi ini belum diketahui dengan pasti, namun secara fenotip sapi Kuantan diduga merupakan hasil persilangan antara sapi Pesisir dengan jenis sapi yang lain. Sapi ini diseleksi oleh peternak dan dipelihara secara turun-temurun, hingga akhirnya diperoreh warna bulu yang cukup beragam. Masyarakat 
Kuantan Singingi sering menyebut sapi tersebut dengan sebutan sapi Kuantan. Sapi Kuantan sangat berpotensi untuk dapat dikembangkan karena memiliki keunggulan, antara lain: mampu hidup di wilayah yang tidak dapat dikembangkan ternak ruminansia lainnya, daya tahan terhadap penyakit tropis tinggi, mampu bertahan hidup dengan kondisi pakan yang kurang dan kualitas rendah, serta respon tingkah laku yang cukup jinak (Sitindaon et al., 2014).

Perkembangbiakan populasi sapi Kuantan tidak terlepas dari kemampuan reproduksi baik ternak jantan maupun ternak betina. Skrotum merupakan pembungkus testis yang merupakan tempat spermatozoa diproduksi. Lingkar skrotum mencerminkan ukuran dari testis dan menyatakan banyaknya jaringan atau tubuli seminiferi yang berfungsi untuk memproduksi spermatozoa (Saputra et al., 2017). Kemampuan reproduksi ternak jantan sangat dipengaruhi oleh organ testis, dimana organ testis merupakan salah satu organ yang bertanggung jawab dalam memproduksi sel spermatozoa. Konsentrasi sperma ternak jantan dipengaruhi oleh nutrisi dalam pakan, organ reproduksi dan sistem hormonal dalam tubuh. Organ reproduksi seperti testis merupakan gambaran kemampuan seekor ternak jantan dalam menghasilkan spermatozoa. Tubuli seminiferi dalam organ testis merupakan tempat pembentukan sperma. Hormon dapat mempengaruhi volume semen dan juga konsentrasi spermatozoa yang dihasilkan oleh sel-sel tubuli seminiferi sehingga dapat mempengaruhi tingkat libido pada ternak jantan. Toelihere (1993) menyatakan bahwa libido berpengaruh terhadap kualitas dan kuantitas semen, sedangkan libido itu sendiri dipengaruhi oleh sekresi hormon testosteron yang dihasilkan oleh testis.

$$
\text { Pembentukan dan pematangan }
$$

spermatozoa di dalam organ testis disebut spermatogenesis. Spermatogenesis yaitu sebuah proses sistematis dan terarah yang meliputi pertumbuhan dan perkembangan spermatozoa dewasa dari sel-sel yang lebih muda serta terjadi di dalam tubuli seminiferi (Feradis, 2010). Proses spermatogenesis secara sempurna baru dimulai setelah ternak mencapai masa pubertas. Produksi sperma akan semakin meningkat dengan bertambahnya umur ternak jantan. Selain itu, besar kecilnya ukuran testis berhubungan dengan kuantitas sperma yang dihasilkan.

Angka kelahiran anak sapi Kuantan masih rendah jika dibandingkan dengan sapi Bali. Hal ini dimungkinkan karena sistem pemeliharaan sapi Kuantan yang belum baik serta kemampuan reproduksi pada sapi Kuantan yang belum maksimal. Permasalahan yang terjadi pada sapi Kuantan yaitu belum ada pembibitan yang terprogram baik dari pemerintah maupun masyarakat. Sapi Kuantan biasanya digunakan sebagai penghasil daging, dipelihara sebagai tabungan yang sewaktu-waktu dapat dijual apabila ada keperluan mendesak. Masyarakat pada umumnya memelihara secara tradisional dengan sistem budidaya yang masih alami (Sitindaon et al., 2014).

Sapi Kuantan memiliki pemasaran yang cukup menarik bagi konsumen karena harganya yang relatif murah. Hal ini yang menyebabkan terjadi tingginya angka penyembelihan dan penjualan sapi pada saat umur muda. Tingginya penjualan sapi Kuantan laku yang tidak diimbangi dengan pembibitan dan pelestarian genetik menyebabkan kemungkinan terjadinya kepunahan (Jiyanto dan Anwar, 2019). Salah satu upaya yang dapat dilakukan dalam hal ini adalah melihat korelasi organ testikuler dengan kualitas spermatozoa sapi Kuantan Riau. Tujuan dari penelitian ini untuk mengetahui hubungan lingkar skrotum dengan kualitas semen sapi Kuantan Riau.

\section{MATERI DAN METODE}

Penelitian ini dilaksanakan selama 2 bulan di Kecamatan Benai Kabupaten Kuantan Singingi, Provinsi Riau. 


\section{Materi Penelitian}

Materi yang digunakan dalam penelitian ini adalah sapi Kuantan pejantan sebanyak 15 ekor dengan umur minimal 2 tahun. Adapun sapi yang digunakan tersebut telah mencapai dewasa kelamin dan dewasa tubuh serta memiliki kemampuan reproduksi yang baik. Alat yang digunakan untuk mengukur lingkar skrotum adalah pita ukur.

Pengambilan data lingkar skrotum dengan menggunakan metode Sorensen (1979) yaitu dengan cara melingkarkan pita ukur pada bagian terlebar dari skrotum. Alat yang digunakan untuk melihat produksi semen adalah mikroskop, vagina buatan, pipet tetes, tabung reaksi, kertas lakmus, cover glass, dan object glass.

\section{Metode Penelitian}

Metode pengambilan sampel dilakukan di Kecamatan Benai menggunakan metode purposive sampling. Sapi jantan Kuantan diperoleh dari desa yang sudah mencapai dewasa kelamin dan dewasa tubuh serta memiliki kemampuan reproduksi yang baik. Data penelitian diperoleh melalui pengukuran dan pengamatan. Semen yang di amati diambil dari cauda epididimis.

Tabel 1. Interpretasi Koefisien Korelasi

\begin{tabular}{cc}
\hline Interval Koefisien Korelasi & Tingkat Korelasi \\
\hline $0,000-0,199$ & Sangat rendah \\
$0,200-0,399$ & Rendah \\
$0,400-0,599$ & Sedang \\
$0,600-0,799$ & Kuat \\
$0,800-1,000$ & Sangat kuat \\
\hline
\end{tabular}

Hasil dari pengukuran dan pengamatan selanjutnya akan dianalisis secara statistik menggunakan analisis korelasi sederhana. Analisis korelasi ( $\mathrm{r}$ ) yang digunakan merupakan nilai tingkat keeratan hubungan antara peubah bebas (X) dengan peubah tak bebas $(\mathrm{Y})$ dan analisis koefisien determinasi $\left(\mathrm{R}^{2}\right)$ yaitu menyatakan besarnya peubah $\mathrm{X}$ yang mempengaruhi peubah Y. Adapun peubah $\mathrm{X}$ adalah lingkar skrotum dan peubah $Y$ adalah volume semen, konsentrasi dan motilitas spermatozoa. Model matematik yang digunakan adalah sebagai berikut.

$$
Y=a+b X
$$

Nilai koefisien regresi (b), digunakan rumus sebagai berikut:

$$
\mathrm{b}=\frac{\mathrm{n} \sum \mathrm{xy}-\left(\sum \mathrm{x}\right)\left(\sum \mathrm{y}\right)}{\mathrm{n} \sum \mathrm{x}^{2}-\left(\sum \mathrm{x}\right)^{2}}
$$

Setelah nilai $b$ diketahui, maka nilai konstanta (a) dihitung dengan rumus:
Keterangan:

$$
\mathrm{a}=\frac{\mathrm{n} \sum \mathrm{x}^{2}-\left(\sum \mathrm{x}\right)^{2}}{\mathrm{n}}
$$

$\mathrm{y}=$ variabel tidak bebas (lingkar skrotum)

$\mathrm{x}=$ variabel bebas (volume semen, konsentrasi dan motilitas spermatozoa)

$\mathrm{a}=$ nilai konstanta

$\mathrm{b}=$ nilai koefisien regresi

$\mathrm{n}=$ jumlah data

Interpretasi nilai koefisien korelasi menurut Sugiyono (2005).

$$
\mathrm{r}=\frac{\mathrm{n} \sum \mathrm{xy}-\left(\sum \mathrm{x}\right)\left(\sum \mathrm{y}\right)}{\sqrt{\left\{\mathrm{n} \sum \mathrm{x}^{2}-\left(\sum \mathrm{x}\right)^{2}\right\} \sqrt{\left\{\mathrm{n} \sum \mathrm{y}^{2}-\left(\sum \mathrm{y}\right)^{2}\right\}}}}
$$

Keterangan:

$r=$ koefisien korelasi

$\mathrm{n}=$ jumlah ternak

$\mathrm{x}=$ variabel bebas

$\mathrm{y}=$ variabel terikat

HASIL DAN PEMBAHASAN 
Hasil pengamatan kualitas spermatozoa dan pengukuran organ reproduksi ternak jantan pada sapi Kuantan diperoleh hasil yang beragam. Ukuran lingkar skrotum terkecil sebesar $22 \mathrm{~cm}$ dan terbesar sebesar $25 \mathrm{~cm}$. Kualitas spermatozoa memiliki viabilitas terendah $70 \%$ dan tertinggi $80 \%$. Motilitas spermatozoa terendah $50 \%$ dan tertinggi $60 \%$. Nilai rata-rata hasil pengukuran lingkar skrotum yaitu $23,06 \pm 1,22 \mathrm{~cm}$ (Tabel 2). Hal ini berbeda dengan hasil penelitian yang dilakukan oleh Saputra et al. (2017) bahwa ukuran lingkar skrotum pada sapi lokal seperti sapi Bali yaitu $30,10 \pm 1,75 \mathrm{~cm}$. Hal ini dapat terjadi karena ternak yang digunakan dalam penelitian ini berbeda dari segi bangsa, umur, dan ukuran tubuh ternak. Sementara pengamatan terhadap kualitas spermatozoa sapi Kuantan meliputi nilai rata-rata viabilitas sebesar $76,67 \pm 4,08 \%$ sedangkan nilai ratarata motilias sebesar $58,00 \pm 3,16 \%$.

Hasil penelitian ini tidak jauh berbeda dengan yang telah dilakukan oleh Wiratri et al. (2013) bahwa pemeriksaan semen segar yang dilakukan pada sapi Limousin menunjukkan nilai viabilitas $78,30 \pm 1,69 \%$ dan motilitas individu $55,00 \pm 0,00 \%$. Toelihere (1993) menjelaskan bahwa standar persentase viabilitas hidup minimal 70\% dari perhitungan minimal 200 sel spermatozoa per preparat.

\section{Regresi}

Hasil analisis sidik ragam yang dilakukan pada lingkar skrotum terhadap viabilitas dan motilitas spermatozoa sapi Kuantan menunjukkan tidak ada perbedaan $(\mathrm{P}>0,05)$. Hal ini menunjukkan bahwa viabilitas dan motilitas lebih dipengaruhi oleh faktor lain daripada lingkar skrotum.

Hasil analisis regresi diperoleh nilai persamaan antara lingkar skrotum dengan viabilitas dan motilitas yaitu masing-masing $\mathrm{Y}$ $=45,44+1,35 \mathrm{X}$ dan $\mathrm{Y}=44,77+0,57 \mathrm{X}$. Berdasarkan dari hasil penelitian ini nilai korelasi antara lingkar skrotum dengan viabilitas dan mortalitas pada sapi Kuantan dapat dilihat pada Tabel 3.

\section{Hubungan Antara Lingkar Skrotum dengan Viabilitas Spermatozoa}

Viabilitas merupakan kemampuan spermatozoa untuk bertahan hidup yang diperlihatkan melalui kesanggupannya bergerak sampai tidak adanya pergerakan lagi (Pramono dan Tagama, 2008). Nilai korelasi antara lingkar skrotum dengan viabilitas spermatozoa sapi Kuantan yaitu 0,40 dengan nilai determinasi 0,16 . Hal ini menunjukkan bahwa terdapat tingkat korelasi yang sedang antara lingkar skrotum dengan viabilitas spermatozoa sapi Kuantan. Tingkat korelasi yang sedang pada hubungan antara lingkar skrotum dengan viabilitas spermatozoa sapi Kuantan yang berarti kualitas viabilitas spermatozoa juga dapat dipengaruhi oleh faktor lain, diantarnya yaitu genetik dan lingkungan (Toelihere, 1993).

Tabel 2. Nilai Rataan Lingkar Skrotum, Viabilitas dan Motilitas Spermatozoa Sapi Kuantan

\begin{tabular}{lccc}
\hline \multicolumn{1}{c}{ Variabel } & Data Terkecil & Data Terbesar & Rataan dan SD \\
\hline Lingkar skrotum (cm) & 22 & 25 & $23,06 \pm 1,22$ \\
Viabilitas (\%) & 70 & 80 & $76,67 \pm 4,08$ \\
Motilitas (\%) & 50 & 60 & $58,00 \pm 3,16$ \\
\hline
\end{tabular}

Hubungan Antara Lingkar Skrotum dengan Motilitas Spermatozoa

Hasil analisis data diatas pada Tabel 3, diperoleh nilai koefisien korelasi antara lingkar skrotum dengan motilitas spermatozoa sapi Kuantan yaitu 0,22. Hal ini menunjukkan bahwa terdapat korelasi positif antara lingkar skrotum dengan motilitas spermatozoa sapi kuantan. Sifat dari hubungan antara lingkar skrotum dengan 
motilitas spermatozoa termasuk dalam kategori nilai korelasi yang rendah. Hal ini dimungkinkan karena lingkar skrotum berbanding lurus dengan produksi semen dan tidak berbanding lurus dengan motilitas spermatozoa. Nilai dari determinasi $\left(\mathrm{R}^{2}\right)$ antara lingkar skrotum dengan motilitas spermatozoa sapi Kuantan yaitu 0,05 yang berarti ukuran lingkar skrotum hanya berpengaruh terhadap motilitas spermatozoa sapi Kuantan sebesar 5\% sedangkan selebihnya 95\% dipengaruhi oleh faktor yang lain. Menurut Herdis (2005) menyatakan bahwa motilitas spermatozoa dipengaruhi oleh perbedaan bangsa ternak dan waktu pemeriksaan.

Tabel 3. Persamaan Regresi dan Nilai Koefesien Korelasi (r) dan Determinasi ( $\left.R^{2}\right)$ Antara Lingkar Skrotum dengan Kualitas Semen

\begin{tabular}{lcccc}
\hline \multicolumn{1}{c}{ Variabel } & Persamaan Regresi & $\mathrm{r}$ & $\mathrm{R}^{2}$ & Signifikansi \\
\hline Viabilitas & $\mathrm{Y}=45,44+1,35 \mathrm{X}$ & 0,40 & 0,16 & $\mathrm{P}>0,05$ \\
Motilitas & $\mathrm{Y}=44,77+0,57 \mathrm{X}$ & 0,22 & 0,05 & $\mathrm{P}>0,05$ \\
\hline
\end{tabular}

Hubungan antara lingkar skrotum terhadap motilitas spermatozoa sapi Kuantan pada penelitian ini memiliki hubungan yang lemah. Hal ini disebabkan karena besarnya ukuran lingkar skrotum sejalan dengan bertambahnya jumlah tubuli seminiferi dalam organ testis yang dapat meningkatkan jumlah spermatozoa yang didukung dengan jumlah seminal plasma, sedangkan motilitas dari spermatozoa dapat dipengaruhi oleh nutrisi pakan, frekuensi ejakulasi dan kondisi lingkungan.

Menurut Khairi (2016) bahwa kondisi lingkungan yang berada pada suhu rendah dan curah hujan tinggi menyebabkan menurunnya motilitas akibat perubahan musim dan lamanya penyinaran dapat menghambat produksi FSH (follicle stimulating hormone) yang menghambat proses spermatogenesis oleh testis. Selain itu motilitas spermatozoa juga dipengaruhi oleh lamanya waktu penanganan setelah spermatozoa berada di luar organ reproduksi. Hasil ini diperkuat oleh pendapat Ismaya (2014) bahwa ejakulat pertama sesudah istirahat yang lama menyebabkan banyak sel spermatozoa yang mati dan menurunkan persentase motilitas spermatozoa. Hubungan antara lingkar skrotum dengan motilitas spermatozoa sapi Kuantan ini hampir sama dengan hasil penelitian Prayogo et al. (2013) bahwa hubungan antara lingkar skrotum tidak berpengaruh nyata terhadap motilitas spermatozoa dengan nilai koefisien korelasi sebesar 0,34.

\section{KESIMPULAN}

Kesimpulan dari penelitian ini adalah terdapatnya korelasi positif antara lingkar skrotum dengan kualitas sperma sapi jantan Kuantan, dengan koefisien korelasi yang bernilai sedang $(0,4)$ untuk viabilitas, dan rendah $(0,22)$ untuk motilitas.

\section{UCAPAN TERIMAKASIH}

Penelitian ini didanai oleh Universitas Islam Kuantan Singingi sebagai wujud dalam pelaksanaan Tri Darma Perguruan Tinggi. Ucapan terimkasih juga kepada LPPM Universitas Islam Kuantan Singingi yang telah memberikan kesempatan dan banyak membantu untuk kelancaran penelitian ini.

\section{DAFTAR PUSTAKA}

Feradis. 2010. Bioteknologi Reproduksi pada Ternak. Alfabeta. Bandung.

Herdis. 2005. Optimalisasi Inseminasi Buatan Melalui Aplikasi Teknologi Laserpuntur pada Domba Garut (Ovis aries). Disertasi. Sekolah Pascasarjana. Institut Pertanian Bogor. Bogor. 
Ismaya. 2014. Bioteknologi Inseminasi Buatan pada Sapi dan Kerbau (Biotechnology of Artificial Insemination on Cattle and Buffalo). Gadjah Mada University Press. Yogyakarta.

Jiyanto dan P. Anwar. 2019. Identifikasi kualitas spermatozoa sapi kuantan riau sebagai pelestarian plasma nutfah ternak lokal. Jurnal Ilmu dan Teknologi Peternakan Tropis. 6(1):52-56.

Khairi, F. 2016. Evaluasi produksi dan kualitas semen sapi simmental terhadap tingkat bobot badan berbeda. Jurnal Peternakan. 13(2):54-58.

Pramono, E. dan T.R. Tagama. 2008. Pengaruh penambahan adenosine triphoshat ke dalam pengancer semen terhadap kualitas spermatozoa domba ekor gemuk. Jurnal Animal Production. 10(3):151-156.

Prayogo, K.U.E., T.R. Tagama, dan Maidaswar. 2013. Hubungan ukuran lingkar skrotum dengan volume semen, konsentrasi dan motilitas spermatozoa pejantan sapi Limousin dan Simmental. Jurnal Ilmiah Peternakan. 1(3):10501056.

Saputra D.J., M.N. Ihsan, dan N. Isnaini. 2017. Korelasi antara lingkar skrotum dengan volume semen, konsentrasi dan motilitas spermatozoa pejantan sapi bali. Jurnal Ternak Tropika. 18(2):4753.

Sintindaon, S.H., Alfiany, dan Istiana. 2014. Identifikasi sumberdaya genetik ternak di Provinsi Riau. Prosiding Teknologi Peternakan dan Veteriner Mendukung Pertanian Bioindustri Berkelanjutan. Pusat Penelitian dan Pengembangan Peternakan. Seminar Nasional Teknologi Peternakan dan Veteriner. Sumatra Utara, 20 Agustus 2014.

Sorensen, A.M. 1979. Animal Reproduction. McGraw-Hill Inc. New York.

Sugiyono. 2005. Metode Penelitian Kuantitatif, Kualitatif, dan R\&D. CV. Alfabeta. Bandung.
Toelihere, M.R. 1993. Fisiologi Reproduksi pada Temak. Angkasa. Bandung.

Toelihere, M.R. 1993. Inseminasi Buatan pada Ternak. Angkasa. Bandung.

Wiratri. V.D.B., T. Susilawati, dan S. Wahjuningsih. 2013. Kualitas semen sapi Limousin pada pengencer yang berbeda selama pendinginan. Jurnal Ternak Tropika. 15(1):13-20. 